\title{
Evaluating the Accuracy of Remote Dendrometers in Tree Diameter Measurements at Breast Height
}

\author{
Zennure Ucar, Ahmet Salih Değermenci, Hayati Zengin, Pete Bettinger
}

\begin{abstract}
An accurate tree diameter (DBH) measurement is a significant component of forest inventory. This study assessed the reliability of remote dendrometers to measure tree $\mathrm{DBH}$. We compared direct caliper measurements (reference measurements) to the remote measurements collected from a laser caliper and a smartphone at $0.5 \mathrm{~m}, 1 \mathrm{~m}$, and $1.5 \mathrm{~m}$ distances from each tree within three forest types (pine, oak, and poplar forests). In general, all remote dendrometers underestimated the mean diameter compared to direct caliper measurements, regardless of forest types and distances. We observed that the mean deviation of direct caliper measurement and smartphone measurement at $1.5 \mathrm{~m}$ within a pine forest and oak forest were the lowest $(0.3 \mathrm{~cm}$ and $0.36 \mathrm{~cm}$, respectively). The deviations between direct caliper measurements and smartphone measurements at a $0.5 \mathrm{~m}$ distance, across forest types, were noticeably larger compared to others. An ANOVA test was used to determine whether significant deviations existed between caliper measurements and remote measurements at a specific distance, and among three different forest types. We rejected the null hypothesis, which suggested that there were no statistically significant differences $(\mathrm{p}<0.05)$ between tree $\mathrm{DBH}$ measurements obtained from the direct caliper measurements and indirect measurements (smartphone and laser caliper) captured at a distance. Then, a post-hoc test was performed to examine which set of estimated deviations was different from the reference data. The results suggested that indirect tree DBH measurements using the smartphone app at $1 \mathrm{~m}$ and $1.5 \mathrm{~m}$ in certain forest types (pine and oak) were not significantly different from direct tree DBH measurements. Also, our test results mostly indicated no significant difference within each forest, except for measurements using the smartphone app at $0.5 \mathrm{~m}$ across all forest types when the smartphone measurements were compared to laser caliper measurements. Although forest characteristics and measurement distance may play an important role in remote tree DBH measurement accuracy, the smartphone app may be used as a practical alternative to direct measurement in measuring the $\mathrm{DBH}$ of a tree, which may be a positive development for forestry due to the increased use of smartphones and the availability of a free measure app.
\end{abstract}

Keywords: precision forestry, laser caliper, smartphone, diameter at breast height

\section{Introduction}

The tree diameter is one of the most important and commonly measured individual tree attributes. It is used to determine tree volume, basal area, and other tree characteristics, which are essential components of a forest inventory, it helps in developing forest management and planning options, and it can be of value in conducting research (Moran and Williams 2002, Melkas et al. 2008, Liu et al. 2011). In most countries, diameter-at-breast height $(D B H)$ is the most common tree diameter measurement. A DBH is described as the outside bark stem diameter of a tree at a point located $1.30 \mathrm{~m}$ above the ground base, on the uphill side of a tree, except in the United States (1.37 m), and Japan and Korea (1.2 m) (van Laar and Akça 2007, Kershaw et al. 2017). Tree $D B H$ can be measured using a number of different devices, or dendrometers, which can be divided into two groups: those that contact the stem physically and those that avoid direct contact and 
facilitate a remote measurement (Ashley and Roger 1969, Clark et al. 2000a, Melkas et al. 2008, Liu et al. 2011). Also, devices can be differentiated based on cost, accuracy, precision, ease of use (Clark et al. 2000a, Liu et al. 2011). Direct contact measurement, using traditional diameter tapes and calipers, is the most common and preferred method for field measurements due to its accuracy, efficiency, and simplicity (Clark et al. 2000a, Luoma et al. 2017). Over the last century, many studies have been conducted to examine and evaluate the accuracy of different direct contact dendrometers such as the Bitterlich sector fork (Liu et al. 2011, Weaver et al. 2015), electronic tree measuring fork (Binot et al. 1995), Biltmore stick (Jackson 1911, Moran and Williams 2002), and the Samoan stick (Dixon 1973). With the exception of calipers and tapes, the reliability and subjectivity of the other direct contact dendrometers may limit their use in scientific or large-scale inventory work (Clark et al. 2000a).

Indirect $D B H$ measurements do not require physical contact with the stem of a tree, and some instruments may be capable of precise measurement from a remote location through statistical, mathematical, and optical processes (Celes et al. 2019). In particular, the development of optical dendrometers pioneered this change. The reviews by Brickell (1976), Grosenbaugh (1963), Clark et al. (2000a) provide more detail about the design, development, evaluation, history, and guidelines for selecting optical dendrometers. One type of indirect method, using photogrammetry techniques based on optical and mathematical methods, has been investigated for use in measuring tree diameters. Marsh (1952) made perhaps the first attempt at using a conventional camera to estimate tree diameters and suggested that accuracy could be $\pm 63.5 \mathrm{~mm}$ and $\pm 20.3 \mathrm{~mm}$, respectively, when using oblique and horizontal photos. Similar studies have described indirect methods for measuring upper stem diameters (Ashley and Roger 1969, Bradshaw 1972, Takahashi et al. 1997). The result of these studies indicated that the accuracy of diameters obtained from the photographs was promising. As technology has evolved, conventional cameras have been replaced by digital cameras that can produce high-quality images at a low cost, and may facilitate more accurate and precise results than film-based camera systems. Also, advances in digital storage and computing power make it efficient to store and process a large number of images (Juujarvi et al. 1998, Dick et al. 2010). Hence, digital cameras may be cost and time-effective and easy to use compared to conventional cameras (Clarke et al. 1995, Clark et al. 2000a, Clark et al. 2000b). Some studies have already tested digital image-based methods for estimating tree diameters. Juujarvi et al. (1998) proposed a method to estimate tree diameter using digital cameras, although a calibration plane was needed in each picture to understand scale. Clark et al. (2000b) also examined the use of a digital camera to assess oak tree $D B H$ in winter and indicated that tree diameters could be estimated from 12 to $15 \mathrm{~m} \pm 40 \mathrm{~mm}$ from a tree.

The development of laser-based devices has also enabled indirect measurement of both tree diameters and heights. Several researchers have tested the accuracy and reliability of the laser-based dendrometers (e.g., Skovsgaard et al. 1998, Williams et al. 1999, Kalliovirta et al. 2005, Weaver et al. 2015). Although the studies suggest that consistent, accurate, and reliable results can be obtained from laser-based dendrometers, it was observed that the distance from the tree, the time needed for tree measurement, and the familiarity with devices played significant roles in the accuracy and reliability of the measurement of tree $D B H$. Since previously the distance to a tree was measured manually, digital cameras have also been integrated with laser instruments. Melkas et al. (2008) used a laser camera to test the diameter measurements under forest conditions. The accuracy of the diameter measurements (standard error) ranged between $5 \mathrm{~mm}$ and $7.6 \mathrm{~mm}$ depending on tree species. Vastantra et al. (2009) compared laser-based field measurements in obtaining tree-level forest data using three different methods (Terrestrial Laser Scanner (TLS), Laser-relascope, and laser camera). The laser camera achieved a low standard error $(8.3 \mathrm{~mm})$ in $\mathrm{DBH}$ measurements compared to the other two methods. Some portable laser scanners, such as backpack LiDAR (Light Detection and Ranging) (Xie et al. 2019), and handheld laserscanning systems (Vatandaşlar and Zeybek 2019), have also been tested to measure tree $D B H$. These two new systems can produce reliable and accurate results in forestry inventory compared to direct measurements, but the stability and the price of the devices need to be taken into account.

Recently, digital cameras have become embedded within smartphones, which have become the most popular and rapidly developing computing device in the last twenty years. Smartphones are relatively easy to use and carry in the forest and can provide high-quality images at a low cost. Images obtained from smartphone cameras have recently been employed for various measurement purposes, such as estimating the chemical properties of soil (Aitkenhead et al. 2020) and indoor navigation and positioning (Yan et al. 2020). Celes et al. (2019) evaluated indirect measurements of tree diameter using images obtained from a smartphone camera 

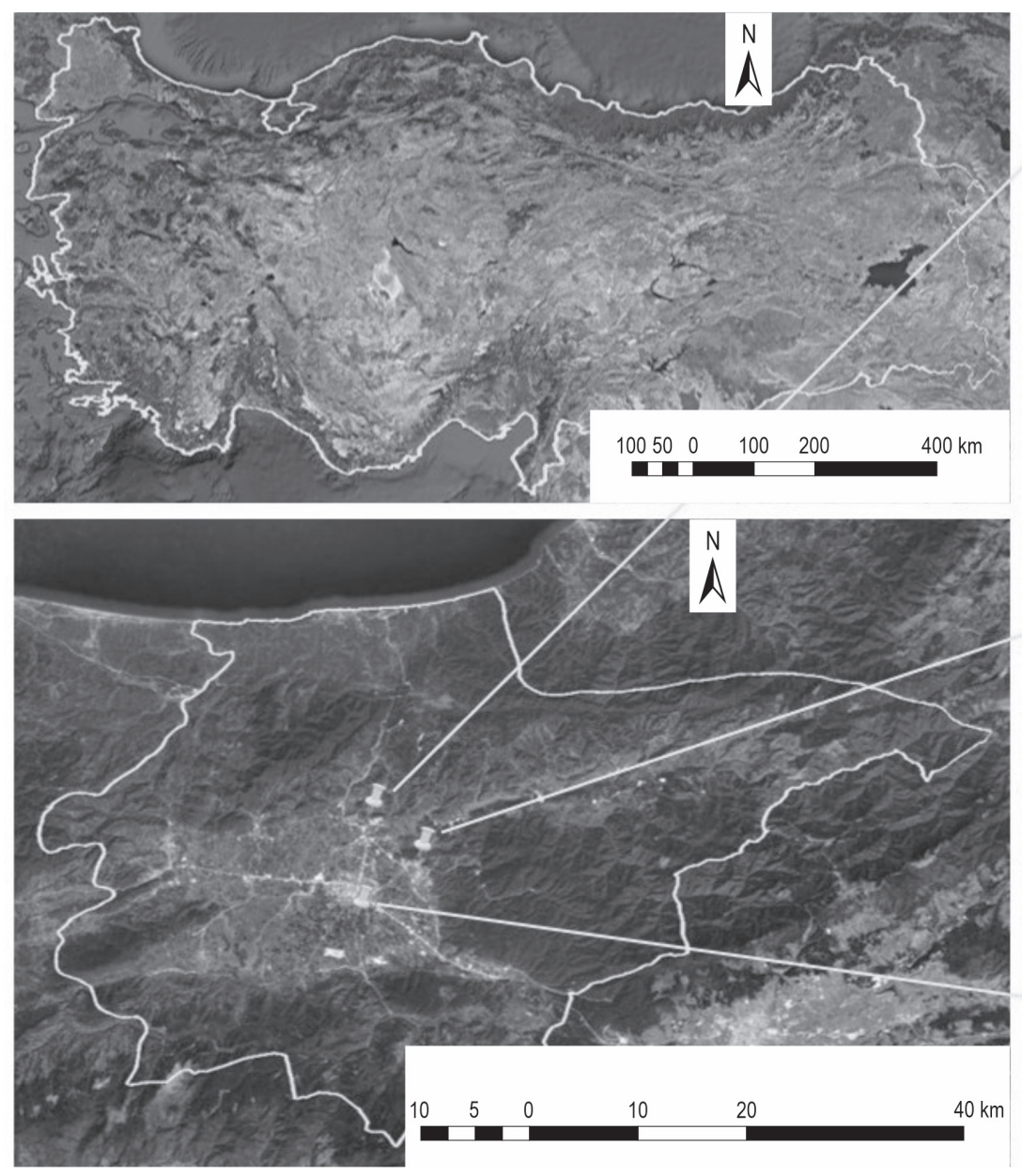

Fig. 1 Location of study area and sample plots

(iPhone 4S) and digital camera (Sony CYBER-SHOT model DSC_HX7) in the Amazon forest. Two cameras showed similar performance within a $1 \mathrm{~cm}$ confidence interval. Some applications (apps) that use the smartphone camera have been developed to estimate tree measurements in a forest sample plot or stand. For instance, the Trestima app interprets images obtained from the smartphone camera and assesses tree characteristics such as diameter, height, and basal area. Vastaranta et al. (2015) examined the accuracy of the Trestima app when used in the boreal forest, and the error for $D B H$ measurements varied between $5.2 \%$ and $11.6 \%$ of $D B H$ depending on the tree species, the number of the images collected, and image shooting locations. Another study by Siipilentho et al. (2016) compared the accuracy and reliability of the same app for determining stand-level characteristics within a boreal forest to airborne laser scanning methods (ALS) and a conventional forest measurement process. The results from the Trestima app produced the most accurate and reliable stand characteristics with the smallest bias. Other similar forestry apps, such as MOTI, have been developed and tested by researchers (Molinier et al. 2016, Silva 2018). However, these apps are often not freely available and are designed for specific regions or tree species.

Within cellular phones, measurement apps that are not explicitly designed for forestry uses have been released continuously, in accordance with advancements in technology. Some of these are freely available and claim they can easily measure any object. Based on this new source of technology, this research project had the objective of evaluating whether a measurement app can feasibly be used as a dendrometer under forest conditions. Hence, we designed a precision forestry study to assess the accuracy of tree $D B H$ measurements obtained using direct contact devices (calipers) and indirect or remote devices (Apple Measure app (using iPhone X) and laser caliper (Haglof Sweden - Gator Eyes Laser Pointer)) operated at several 
distances from a tree. We further examined whether data collected in different forest types might result in significant differences in tree $D B H$ measurements.

\section{Methods}

\subsection{Study Area}

The study area is located in the western Black Sea Region of Turkey, in the center of Düzce Province $\left(40^{\circ} 37^{\prime} 18^{\prime \prime}-41^{\circ} 06^{\prime} 58^{\prime \prime} \mathrm{N}\right.$ and $\left.30^{\circ} 50^{\prime} 14^{\prime \prime}-31^{\circ} 51^{\prime} 13^{\prime \prime} \mathrm{E}\right)$, and approximately $230 \mathrm{~km}$ east of Istanbul. Düzce Province is relatively flat and surrounded by mountains. The elevation of the city ranges from $100 \mathrm{~m}$ to $1800 \mathrm{~m}$.

For this study, trees were measured in three different forest types: pine, poplar, and oak forests. These forests (Fig. 1) are usually used for field practices by Düzce University, Faculty of Forestry, even though the owners are different. The size of the plots was approximately $600 \mathrm{~m}^{2}, 700 \mathrm{~m}^{2}$, and $590 \mathrm{~m}^{2}$ in the pine, oak, and poplar forests, respectively. The plot in the pine forest, which belongs to the municipality (planted for public use), is composed of only maritime pine (Pinus pinaster) and is placed on a southern aspect with a $25 \%$ slope and an elevation of $285 \mathrm{~m}$ above sea level. The plot in the oak forest, which is owned by Duzce University, is comprised of Turkey oak (Quercus cerris). The average slope and elevation of the plot is $30 \%$ and $285 \mathrm{~m}$ above sea level, respectively. The poplar plot is located in a private industrial plantation forest composed of common aspen (Populus tremula L.), on relatively flat topography with a $150 \mathrm{~m}$ elevation. Each of the forest types where these plots were located has different characteristics (Table 1) that may directly or indirectly affect the measurements. The different tree species were selected to assess potential measurement discrepancies due to differences in bark characteristics, such as color and texture, and the amount of the light that penetrates each forest as a function of the tree density and canopy closure (Liu et al. 2001, Moran and Williams 2002, Weaver et al. 2015).

\subsection{Data}

In addition to direct measurements of tree $D B H$ using a caliper, two indirect measurements were made using a laser caliper and smartphone (Fig. 2). We evaluated the iPhone X (Apple Inc.), released in 2017, which contains a 12-megapixel rear camera system equipped with dual optical image stabilization and a

Table 1 Characteristics of forest types

\begin{tabular}{|l|c|c|c|c|c|c|}
\hline Forest type & Approximate age, years & Average height, $\mathrm{m}$ & Average diameter, $\mathrm{cm}$ & Stem count, trees/ha & Canopy closure, $\%$ & Basal area, $\mathrm{m}^{2} / \mathrm{ha}$ \\
\hline Pine & 30 & 14 & 25.94 & 652 & 73 & 26.1 \\
\hline Oak & 75 & 15 & 28.42 & 570 & 65 & 26.4 \\
\hline Poplar & 7 & 18 & 23.62 & 900 & 78 & 27.9 \\
\hline
\end{tabular}
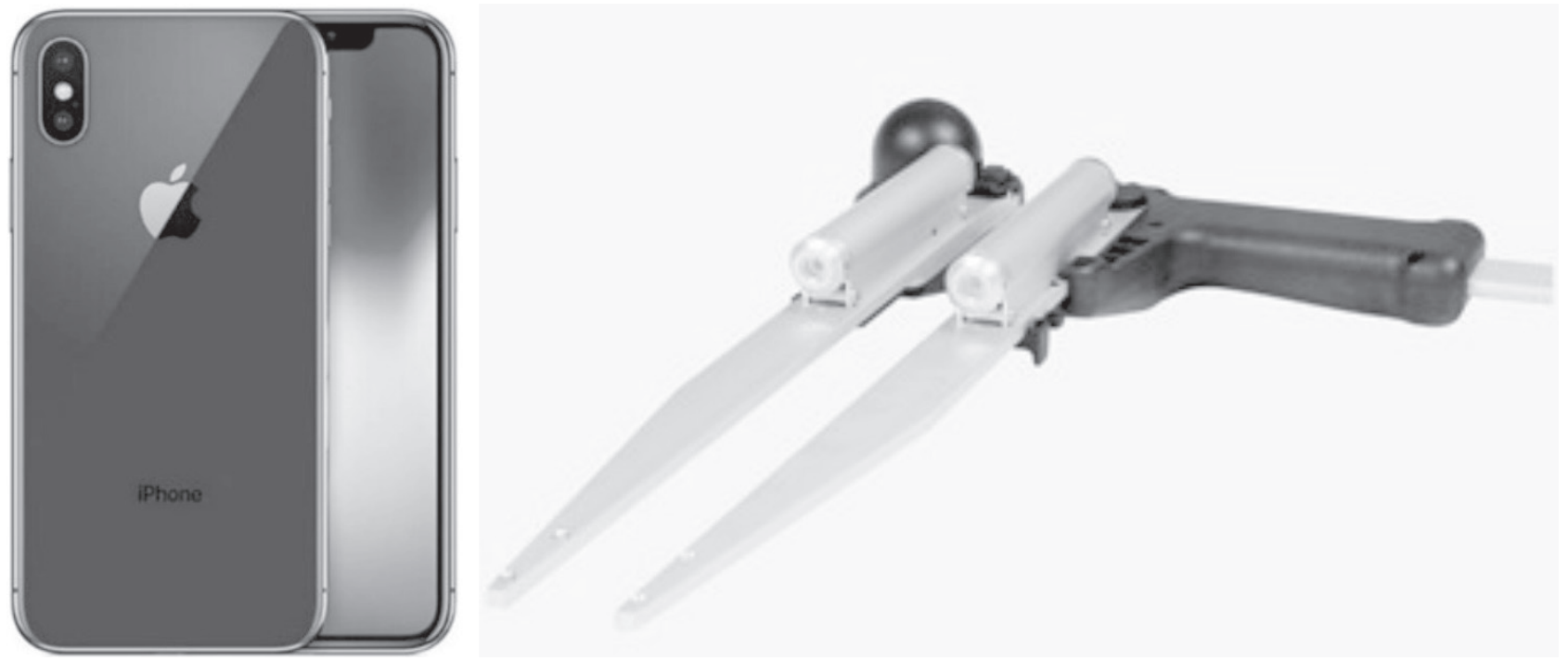

Fig. 2 Remote measurement devices that were used to measure tree diameters in the study 
$14.7 \mathrm{~cm}$ (5.8 inches) super retina display. Within the iPhone $X$, we employed a measurement app that was released by Apple in 2018. The app can quickly estimate the size of the object, and automatically detect the dimension of rectangular objects. It also has a level that can be used to optically straighten a vertical object or level a flat surface. The app also allows users to save an image of the measurement with a userfriendly interface (Fig. 3). In this study, we also evaluated the Haglof Sweden Gator Eyes (Haglöf Sweden $\mathrm{AB}$ ) laser pointer for indirect tree $\mathrm{DBH}$ measurement.
This laser caliper is useful when there are obstacles such as water bodies, understory, and windthrow that make accessing the tree for direct measurement of $D B H$ difficult. Further, it can allow measurement of upper stem diameter measurements and allow users to make tree diameter measurements from a certain distance (perhaps up to $40 \mathrm{~m}$ in daylight).

When collecting data to obtain statistical stability and assess accuracy and precision, repeated measurements are necessary. In this study, 35 trees were randomly selected within each forest type to be measured.

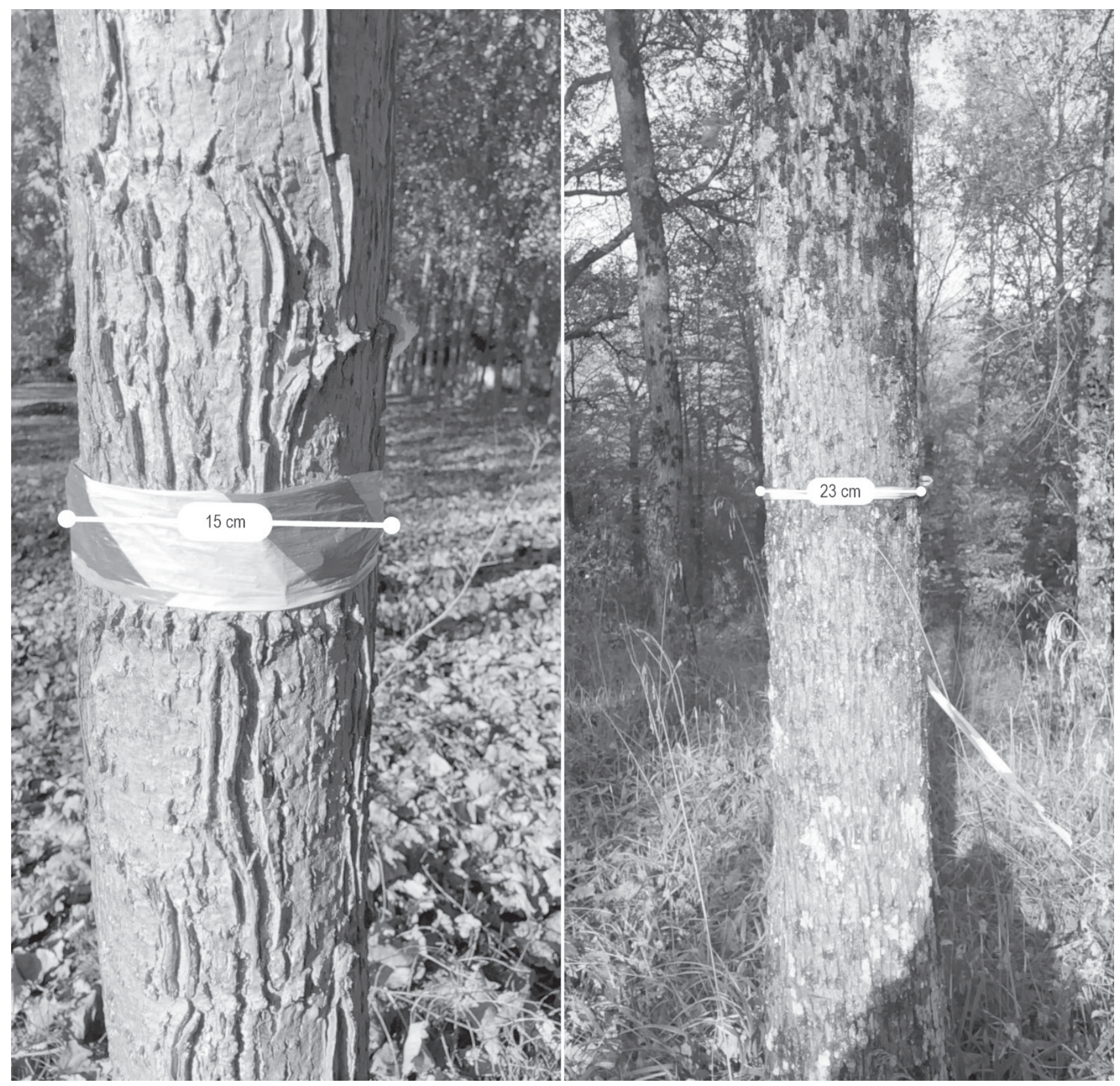

Fig. 3 The view from smartphone app tree $D B H$ measurement of a poplar tree (left) and a oak tree (right) at different distances 
Before starting the measurements of $D B H$ outside the bark at $1.30 \mathrm{~m}$ above ground, the $D B H$ location was marked on the trees with masking tape to make sure that measurements with all devices were made at the same place. The aim of marking the location of the measurement is to reduce discrepancies among the three DBH measurements of trees (Weaver et al. 2015, Božić et al. 2020). During the study period, we visited each tree once to collect all seven diameter measurements. These seven diameter measurements included six remote measurements using two different devices (smartphone and laser caliper at distances of $0.5 \mathrm{~m}, 1 \mathrm{~m}$, $1.5 \mathrm{~m}$ from each tree) and one direct measurement (caliper). All measurements were made along a consistent line of sight from each tree. Therefore in each forest type, we collected 35 measurements of tree $D B H$ from 7 different perspectives (direct, smartphone at 3 distances, laser caliper at 3 distances), for a total of 245 measurements within each forest type. In total, we collected 735 measurements across all three forest types. A single person used the laser caliper for laser caliper measurement and direct measurement (as in Weaver et al. 2015), and another person used the smartphone. Therefore, the caliper measurements should not have been impacted severely by variation in human cognition and performance, as was noted in Božić et al. (2020), since only one person conducted these measurements.

The data collected with the caliper (direct measurement) and laser caliper (indirect measurement) were recorded to the nearest $0.1 \mathrm{~cm}$. However, the smartphone measurement app was not able to measure the diameter to this precision. Thus, data collected with the smartphone were recorded as an integer to the nearest $\mathrm{cm}$ (Fig. 3). The distances from each tree were measured using a laser device (Leica Disto D510 (Leica Geosystems AG)). After randomly selecting the first tree within each forest type and collecting the seven diameter measurements, the next sample tree was selected in a clockwise manner. If a tree was positioned on a hill, we measured the tree from the uphill side. The data were collected in the morning and afternoon for pine, oak, and poplar forest type, respectively, over three days (between mid-October to early November 2019 when the trees still have the leaves). At this specific time of the day, sun rays generate a consistent line of sight with the trees while collecting data. Even though we did not evaluate the relation between light conditions and diameter measurements, we wanted to assess the performance of iPhone $X$ and laser caliper while capturing the edge of bright tree stems. Another study (Weaver et al. 2015) suggested that light conditions were not significantly correlated with the diameter measurement accuracy of a laser caliper.

In this study, our primary interest was to evaluate the difference between the direct caliper measurement and the remote measurements made with laser caliper and smartphone at a distance from each tree. Hence, the direct caliper measurement was used as »true or reference diameter « to estimate the deviation between the direct measurement and the remote measurements made with the laser caliper and smartphone for tree $i$ at a specific distance $d$ in forest type $j$ (Weaver et al. 2015).

$$
D E V_{\mathrm{idj}}=D B H_{\mathrm{i} 0 \mathrm{j}}-D B H_{\mathrm{idj}}
$$

Where:

$D E V_{\text {idj }}$ deviation in diameter values from the laser caliper or smartphone $D B H$ value for tree $i$ at a specific distance $d$ in forest type $j$.

$D B H_{\mathrm{i} 0 \mathrm{j}}$ direct caliper measurement for tree $i$ in forest type $j$.

$D B H_{\text {idj }}$ represents the laser caliper or smartphone $D B H$ measurement for tree $i$ in forest type $j$, obtained at distance $d$ and could either be smaller or larger than $\mathrm{DBH}_{i 0 j}$.

The deviation between direct caliper measurements and distance $d$ measurements in a forest type $j$ was expected to be normally distributed around zero, representing no deviation. However, placing laser lights precisely on the edge of each tree or capturing the edge of the tree with the smartphone camera was not easy due to a combination of bark and light conditions (increase of surface brightness of the bark or shadow effects within crevasses of the bark).

Analysis of variance (ANOVA) was performed using SPSS software (IBM Corp. 2013) on the deviation between caliper measurements and remote measurements to examine the effects of distance, dendrometer types, and forest types. ANOVA is a well-known and frequently used method to compare the means of more than two groups to determine whether at least one group mean was statistically different from the others (Moder 2010, Allen 2017). Before performing the statistical test, the assumptions of the ANOVA, which are the normal distribution of data, independent samples, and homogeneity of variance, were assessed. Six deviations were generated for each forest type (the difference between caliper and remote measurements (smartphone and laser caliper)) at a distance. In total, there were 18 deviations from three different forest types. Also, a reference deviation was added as zero for direct caliper measurements of thirty-five trees to test which measurements have the mean deviation 
Table 2 Mean tree diameter and standard deviation of tree diameters by forest and measurement type

\begin{tabular}{|c|c|c|c|c|c|c|}
\hline \multirow{2}{*}{ Sample measurement } & \multicolumn{2}{|c|}{ Pine forest } & \multicolumn{2}{|c|}{ Oak forest } & \multicolumn{2}{|c|}{ Poplar forest } \\
\hline & Mean, cm & $\mathrm{SD}^{*}, \mathrm{~cm}$ & Mean, cm & $\mathrm{SD}^{*}, \mathrm{~cm}$ & Mean, cm & $\mathrm{SD}^{*}, \mathrm{~cm}$ \\
\hline Caliper - $0 \mathrm{~m}$ & 25.13 & 6.52 & 27.70 & 6.43 & 22.92 & 5.80 \\
\hline iPhone - $0.5 \mathrm{~m}$ & 22.63 & 5.26 & 25.60 & 5.72 & 20.66 & 4.84 \\
\hline iPhone - $1 \mathrm{~m}$ & 24.34 & 5.98 & 26.66 & 6.15 & 21.66 & 5.21 \\
\hline iPhone - 1.5 m & 24.83 & 6.21 & 27.34 & 5.83 & 21.86 & 5.42 \\
\hline Laser caliper - $0.5 \mathrm{~m}$ & 24.13 & 6.72 & 26.36 & 6.30 & 21.66 & 5.75 \\
\hline Laser caliper - 1 m & 24.09 & 6.57 & 26.30 & 6.34 & 21.73 & 5.96 \\
\hline Laser caliper - 1.5 m & 24.06 & 6.64 & 26.28 & 6.27 & 21.55 & 5.85 \\
\hline
\end{tabular}

${ }^{*}$ Standard deviation

close to zero (true or reference measurements). Then, we tested whether each set of laser caliper and smartphone measurement deviations for a specific distance $d$ was normally distributed. According to KolmogorovSmirnov, Shapiro-Wilk, Skewness and Kurtosis tests, and Histogram and Q-Q plots, sets of deviations for all cases (18) were normally distributed.

Except for homogeneity of variance, which was determined using Levene statistical test, the results indicated that the equal variance assumption was not met $(p<0.05)$ (Levene 1960). The two assumptions for the ANOVA test, normal distribution of data and independent samples, were met in our study. However, when the sample size is large and equal, the validity of the ANOVA is minimally affected by violations of the assumptions of homogeneity of variance (Moder 2010, Weinberg and Abramowitz 2016, Allen 2017). Thus, an ANOVA test was performed in the study to determine whether the deviations between direct diameter readings from a caliper (a reference or true measurements) and indirect measurements from two remote dendrometers (laser caliper and smartphone) at a specific distance and among three different forest types were significantly different $(p=0.05)$. If a significant difference was observed, Dunnett's C test (Dunnett 1980, Day and Quinn 1989, Shingala and Rajyaguru 2015) was performed at $p=0.05$ level for pairwise comparisons between the set of direct diameter measurements and each of the 18 sets of indirect measurements.

\section{Results}

The mean $D B H$ measurements within the three forest types and the related measurement processes (Table 2) suggested that tree $D B H$ values measured using the caliper (direct measurement) were larger than the measurement of $D B H$ assessed using the two remote dendrometers regardless of the distance from a tree. Also, it seems that the average diameter estimated using the smartphone produced values closer to reference diameter (direct caliper measurement) when positioned farther away from the tree within each forest type. On the contrary, the difference between the mean diameter measured using a laser caliper and reference diameter tended to increase the farther one moved away from the tree within each forest type, except for the poplar forest. Even though the size of trees in each forest type was relatively similar, measurements from the poplar forest exhibit lower variation than measurements from the pine and oak forests (Table 2). This trend can be noticed in the direct measurement (caliper $-0 \mathrm{~m}$ ), suggesting that tree $D B H$ values were more similar in the poplar forest than in the other two study sites. Interestingly, smartphone measurements always had smaller variations compared to $D B H$ measurements collected with other dendrometers, across all forest types.

When comparing the deviation in diameters with the caliper measurements $(0 \mathrm{~m})$ within each forest type, the results indicate that all remote measurements seem to underestimate tree diameter (Fig. 4). The laser caliper measurements show a noticeably larger amount of variation in diameter values than the smartphone measurements for individual trees, across all forest types, in particular measurements in the pine and oak forests as compared to those in the poplar forest (Table 2). The deviation values (from the reference $D B H$ ) tend to decrease slightly the farther one moves away from a tree when using the smartphone. In addition to this, we observed that the mean deviation of 
direct caliper measurement and smartphone measurement at $1.5 \mathrm{~m}$ within the pine forest (Fig. 5) and the mean deviation of direct caliper measurement and smartphone measurement at $1.5 \mathrm{~m}$ in the oak forests were the lowest $(0.3 \mathrm{~cm}$ and $0.36 \mathrm{~cm}$, respectively). Interestingly, deviations between direct caliper measurements and smartphone measurements at a $0.5 \mathrm{~m}$ distance, across forest types, were noticeably larger compared to others, and all deviations in the poplar forest were larger than $1 \mathrm{~cm}$.

The results of ANOVA performed on computed deviations indicated that there were statistically significant differences $(p<0.05)$ between tree $\mathrm{DBH}$ measurements obtained from the direct caliper measurements and indirect measurements (smartphone and laser caliper) captured at a distance. It was assumed that the deviations between direct and indirect measurements would equal to zero regardless of the distance and forest type. However, the statistical test results indicated that at least one set of deviations were not equal to zero. Thus, we rejected the null hypothesis.

Based on this statistical test result, post-hoc tests were performed to examine which set of estimated deviations (difference between direct reference measurements and indirect measurements of the two dendrometers/distance/forest type sets) was significantly different from the reference data. According to the homogeneity of the variance test result (Levene Statistic), an equal variance was not assumed $(p<0.05)$. Hence, due to the large and equal number of sample sizes, Dunnett's $C$ test was performed at $p=0.05$ level for pairwise comparisons using the estimated deviation (the difference between reference deviation (zero) and computed deviations obtained from direct caliper measurement and two remote dendrometers measurements). When examining the result of Dunnett's C pairwise comparison at a distance within a pine forest, significant differences were observed between direct measurements and laser caliper measurements at all tree distances. However, no significant difference was observed at $1 \mathrm{~m}$ and $1.5 \mathrm{~m}$ distances when using the smartphone. Therefore, mixed results were found from measurements collected in the pine forest. Also, tree $D B H$ measurements were compared between the two indirect dendrometers at all distances using the deviation as the test statistic. These test results showed that samples measured using smartphones and laser calipers at a distance were not significantly different from each other, except in the case of the samples obtained from the smartphone at a $0.5 \mathrm{~m}$ distance.

When examining the difference between direct measurements and the sets of indirect measurements
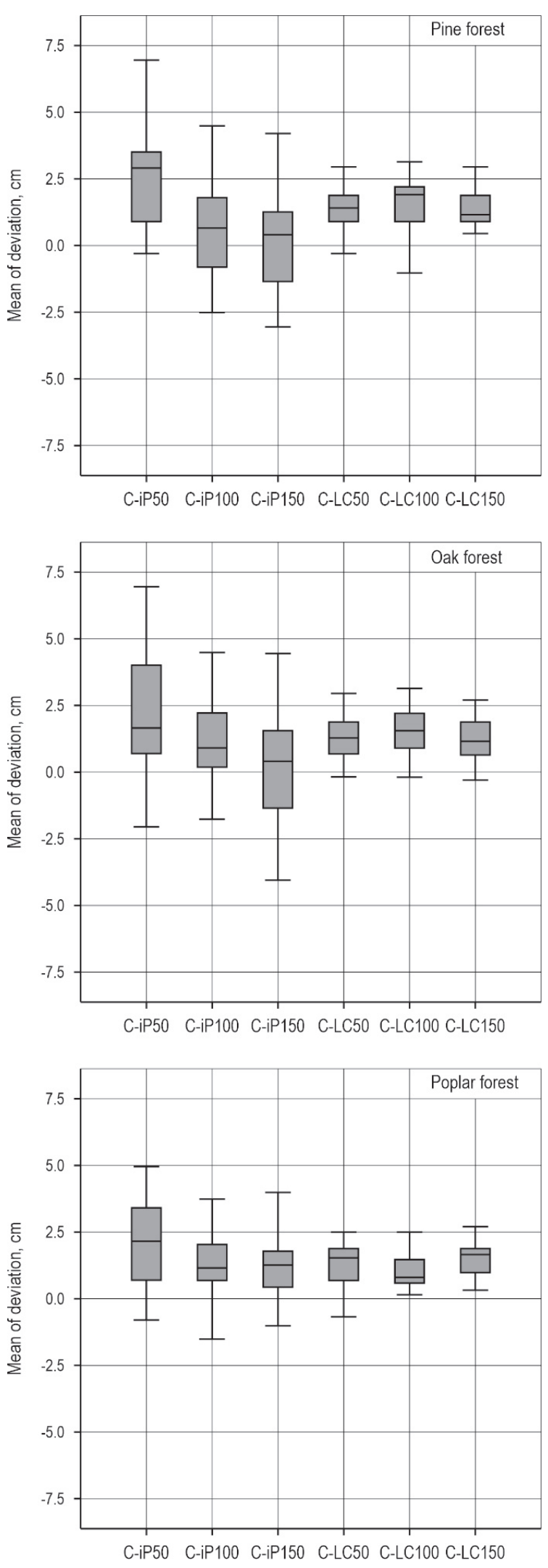

Fig. 4 Box-and-whisker plot of the deviation in tree diameters when compared to the $0 \mathrm{~m}$ (direct) caliper measurements 


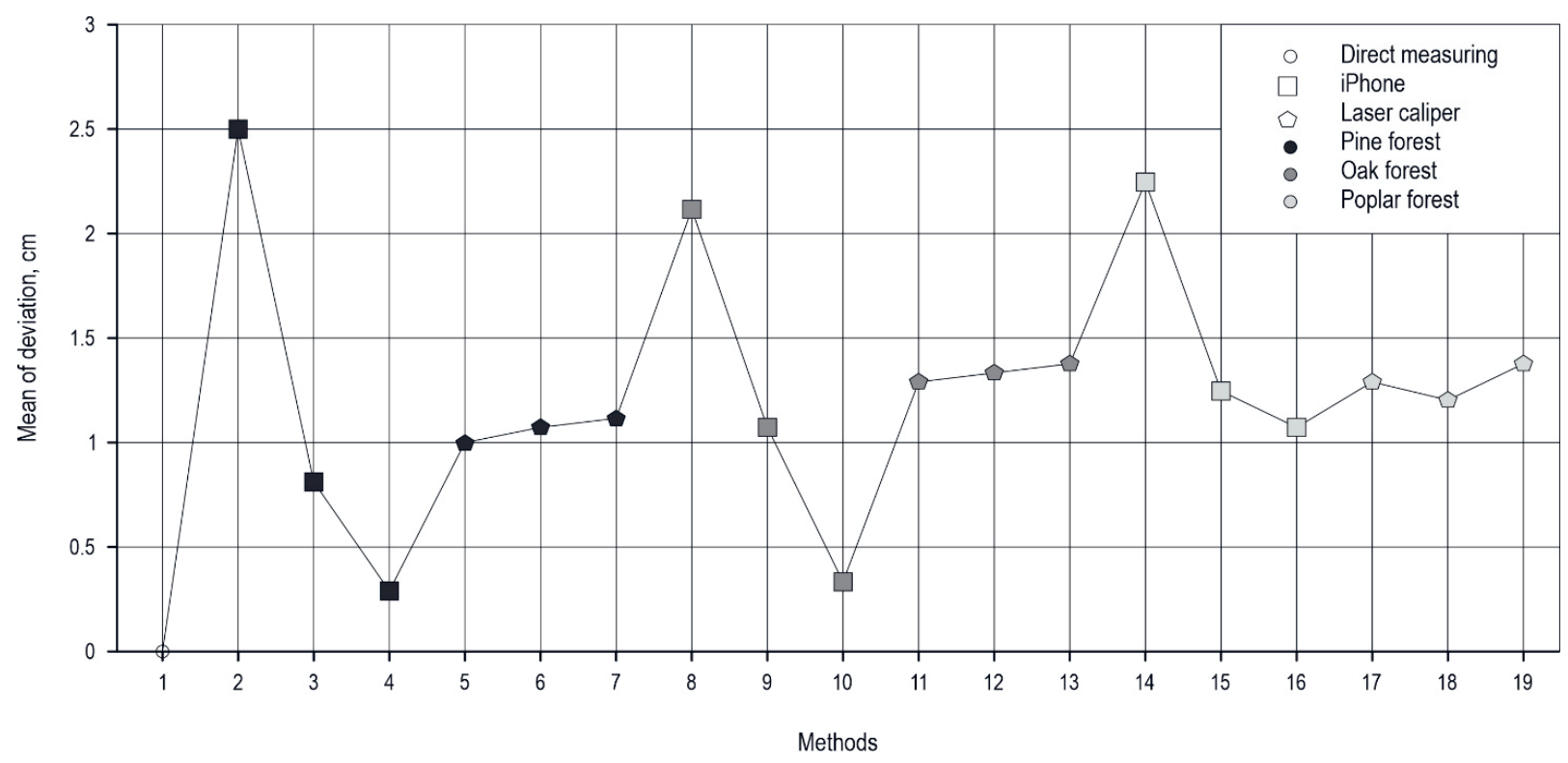

Fig. 5 Mean deviation of tree diameters by forest and measurement type. $(1$ indicates reference deviation zero $(0 \mathrm{~cm})$ from direct measurement. 2, 3 and 4 are deviations at $0.5 \mathrm{~m}, 1 \mathrm{~m}$, and $1.5 \mathrm{~m}$ by iPhone in pine forest, respectively. 5, 6, and 7 are deviations at $0.5 \mathrm{~m}, 1 \mathrm{~m}$, and $1.5 \mathrm{~m}$ by laser caliper in pine forest, respectively. 8,9 and 10 are deviations at $0.5 \mathrm{~m}, 1 \mathrm{~m}$, and $1.5 \mathrm{~m}$ by iPhone in oak forest, respectively. 11,12 and 13 are deviations at $0.5 \mathrm{~m}, 1 \mathrm{~m}$, and $1.5 \mathrm{~m}$ by laser caliper in oak forest, respectively. 14,15 and 16 are deviations at $0.5 \mathrm{~m}, 1 \mathrm{~m}$, and $1.5 \mathrm{~m}$ by iPhone in poplar forest, respectively. Finally, 17, 18 and 19 are deviations at $0.5 \mathrm{~m}, 1 \mathrm{~m}$, and $1.5 \mathrm{~m}$ by laser caliper in poplar forest, respectively.)

within the oak forest, we rejected the null hypotheses for the samples obtained at all distances when using the laser caliper and when using the smartphone at a $0.5 \mathrm{~m}$ distance. In the case of the pine forest there were no significant differences between direct caliper measurements and measurements obtained at $1 \mathrm{~m}$ and $1.5 \mathrm{~m}$ when using the smartphone. In addition, when comparing tree diameter measurements obtained from two remote measurements at a distance, there was no significant difference between smartphone and laser caliper within the oak forest.

When examining differences between direct measurements and remote measurements (smartphone and laser caliper) within the poplar forest, we rejected the null hypothesis for both remote dendrometers (smartphone and laser caliper). This suggests that tree $D B H$ measurements obtained from two remote dendrometers at a distance $(0.5 \mathrm{~m}, 1 \mathrm{~m}$, and $1.5 \mathrm{~m})$ were significantly different from the direct measurements. In comparing the set of tree $D B H$ values between the two remote dendrometers, we found mixed results. The tree $D B H$ measurements using the smartphone at a $0.5 \mathrm{~m}$ distance were significantly different from the tree $D B H$ measurements obtained by the smartphone at $1.5 \mathrm{~m}$ and from the laser caliper at a $1 \mathrm{~m}$ distance. However, all other sets of samples $D B H$ measure- ments were not significantly different when the deviation values were compared.

While assessing differences between forest types, the deviation between direct and indirect measurements (smartphone and laser caliper) was also used as the test statistic. Interestingly, when comparing the deviation values at all distances when using either remote measurement device, there was no significant difference among the pine, oak, and poplar forest types. For a given distance from a tree, both devices tended to behave in a similar manner regardless of the forest type.

\section{Discussion}

The study aimed to evaluate the reliability of remote dendrometers for tree $D B H$ measurements, an essential parameter in forest inventory, used to estimate the economic value of trees, stands, and forests. From our results, the type of dendrometer selected for indirect tree $D B H$ measurement can affect the accuracy of a forest inventory. This is important since, with recent technological development, the forestry field may be shifting from conventional dendrometers (calipers, tapes) to new measuring equipment such as laser calipers, digital cameras, and smartphones. The intent of 
this shift is to improve the accuracy of an inventory and reduce time and cost spent on the data collection process. However, the effect of biased estimates of basic forest measurements on the overall value of a forest enterprise should be considered in these transitions.

In our study, a direct measurement of tree $D B H$ was compared with indirect measurements within different forest types at three different distances. All remote dendrometer measurements seemed to underestimate the tree $D B H$ values according to our results. Also, the use of the smartphone tended to result in a considerably larger amount of variation across forest types, particularly when used relatively close to a tree $(0.5 \mathrm{~m})$, perhaps due to the perspective observed by the devices. When using a camera, distances further away from a tree will allow a better determination of the appropriate sides of a tree on which to determine $D B H$. As we showed, the mean tree diameter and the deviation estimated from smartphone measurements were often closer to the mean diameter value of direct caliper measurements and reference deviations (0) when moved further away from the tree. This finding is in contrast to the Takahashi et al. (1997) study that indicates that, when the distance to the tree increases, measurement error from the camera tends to become larger. However, the mean tree diameter and the deviation estimated when using the laser caliper produced $D B H$ values closer to the direct caliper measurements when used nearer to the trees. Our finding is similar to recent results of Weaver et al. (2015) study, where a slight increase in the variation of laser caliper measurement was found moving farther away from a tree. Some of the variations in laser caliper measurements might relate to human-caused error; the laser caliper requires more skill and attention to detail than a smartphone. Some sources of error when using the laser caliper include not always holding it at the appropriate height, not pointing precisely to the edge of a tree, or visibility issues associated with the edge of a tree.

The results of this study indicated there were significant differences in tree $D B H$ measured directly using a caliper and using both laser caliper and smartphone at a distance. Our study was conducted in three different forest types (pine, oak, and poplar forest). Measured trees in the poplar forest had lighter bark color and smoother surface compared to the trees in pine and oak forests. The trees in the oak forest also had a darker color and rougher structure than the trees in the other forest types. These conditions may have affected the ability to point to the edge of a tree with a laser caliper, and to the ability to capture an image of the edge of a tree with a smartphone camera. At times, we observed that the light of the laser caliper could not be adequately seen, or the edge of a tree could not be captured appropriately by the smartphone on the marked tape (which is white and red) due to brightness issues. Hence, during the laser caliper data collection process, we first targeted a part of a tree stem which was darker than the tape, then moved the laser positions onto the tape. Although Weaver et al. (2015) found that there was no significant correlation between light conditions and the accuracy of $\mathrm{DBH}$ measurements determined by a laser caliper, we observed in our work that very localized light conditions involving the color and brightness of the bark of trees may have had an impact on remotely obtained tree diameter measurements. These light conditions are also related to nearby obstructions and the condition of each tree (reflectance from the bark). Finally, although the trees in our study were marked with a tape at the $D B H$ height, the research site conditions were as realisitic as possible. The trade-off between operational practicality and research rigor is often a struggle, as research requires methodology that maintains the precision of the repeatable measurements. Thus marking the point on each tree where $D B H$ was repeatedly measured on each tree was important, as noted in other works (Weaver et al. 2015, Božić et al. 2020) even though this is not typical in practice.

We further analyzed whether different forest types might cause a difference in the measurement of tree $D B H$ using the same dendrometer at the same distance. For example, the estimated deviation (direct caliper measurements smartphone measurement) at $0.5 \mathrm{~m}$ in the pine forest was used in the pairwise comparison test along with an estimated deviation at $0.5 \mathrm{~m}$ in the oak forest and an estimated deviation at $0.5 \mathrm{~m}$ in the poplar forest. The results showed there was no significant difference in indirect measurements at any distance across forest types. However, when the two remote dendrometers were compared to themselves (at different measurement distances) and each other within each forest type, some interesting results were observed. Samples measured at any distance using the smartphone or laser caliper were generally not different than samples collected by these devices at the same distance across forest types. Nevertheless, differences were observed between devices/distances within the pine and poplar forest types. Like the previous line of discussion, both distances to tree and bark characteristics of trees (color, textures) may have a combined impact on the measurement of tree $D B H$ within and among the forest types, rather than these acting separately (Williams et al. 1999, Clark et al. 2000a).

As one of the dendrometers in the study uses an image to determine tree $\mathrm{DBH}$ measurements, it is 
necessary to take in account the quality of the image, which is related to technical specifications of the smartphone camera, and the sharpness of an image. With a 12-megapixel rear camera system and dual optical image stabilization, the smartphone seems to be capable of capturing a high-quality image. However, technology continues to advance, and in the feature, one should expect even greater quality from these devices. According to results of the pairwise comparison, we observed that tree $D B H$ measurements using smartphones at $1 \mathrm{~m}$ and $1.5 \mathrm{~m}$ distances produced statistically similar results as direct caliper measurements in both pine and oak forest. Celes et al. (2019) reported that using the smartphone camera to measure tree diameter produced similar results as other regular digital cameras, even though the image quality of a smartphone was not as good as one from a conventional digital camera. With the exception of capturing an image too close to a tree, our study seems to be consistent with others that have indicated that the use of a smartphone app in the measurement of tree attributes may facilitate rapid and adequate measurements with low error (Vastaranta et al. 2015, Molinier et al. 2016, Siipilehto et al. 2016).

In general, we observed that remote dendrometers (smartphone and laser caliper) underestimated the mean diameter compared to direct caliper measurements. On the other hand, we also noted that indirect tree $\mathrm{DBH}$ measurements using smartphones resulted in no statistical difference from direct, reference tree $D B H$ measurements in certain forest types (pine and oak) and when captured at certain distances from a tree $(1 \mathrm{~m}$ and $1.5 \mathrm{~m})$. Further, laser calipers may still be useful for measuring tree attributes in areas covered with dense understory, where direct measurement or images collected by smartphones are not possible. The results of our study suggest that the use of the smartphone app to measure the $D B H$ of a tree may be a practical alternative to direct measurement, which may be a positive development for forestry due to the increase in the use of smartphones and the availability of a free measure app.

\section{Conclusions}

The number of smartphone users continues to increase, as does the quality of smartphone technology. The extensive use of smartphones in our daily lives has prompted a new area of utilization of technology, as they are relatively easy to carry and almost always within reach of people. These technologies have begun to be integrated into forest inventory processes, so it is necessary to make assessments of their accuracy and precision. In this study, we evaluated the accuracy of remote dendrometers to measure tree $D B H$. In particular, we assessed the concept of using a freely available smartphone measurement app, which is not designed for forestry applications, as a remote dendrometer. In general, we found that indirect measurements from remote dendrometers tend to underestimate the mean tree $D B H$ regardless of forest type and distance at which they are used. However, the most critical findings from the pairwise comparisons were that tree $D B H$ measurements using the smartphone app at $1 \mathrm{~m}$ and $1.5 \mathrm{~m}$ distances within pine and oak forests were not significantly different from direct reference measurements. Also, when comparing the smartphone measurements to laser caliper measurements, our test results mostly indicated no significant difference within each forest type, except for measurements using the smartphone app at $0.5 \mathrm{~m}$ across forest types, perhaps due to the perspective of the devices.

\section{Acknowledgment}

This work was supported by the Department of Forest Engineering, Faculty of Forestry, Duzce University. We would also like to thank our senior forestry student who helped us to collect data and all authors who contributed to the planning, analyses, and writing process of the article.

\section{References}

Aitkenhead, M.J., Poggio, L., Wardell-Johnson, D., Coull, M.C., Rivington, M., Black, H.I.J., Yacob, G., Boke, S., Habte, M., 2020: Estimating soil properties from smartphone imagery in Ethiopia. Computers and Electronics in Agriculture 171: 105322. https://doi.org/10.1016/j.compag.2020.105322

Allen, M. (Ed.), 2017: The SAGE encyclopedia of communication research methods. SAGE Publications, Inc., Thousand Oaks, CA. http://dx.doi.org/10.4135/9781483381411

Ashley, M.D., Roger, R.E., 1969: Tree heights and upper stem diameters. Photogrammetric Engineering 35(2): 136-146.

Binot, J.M., Pothier, D., Lebel, J., 1995: Comparison of relative accuracy and time requirement between the caliper, the diameter tape and an electronic tree measuring fork. The Forestry Chronicle 71(2): 197-200. https://doi.org/10.5558/ tfc71197-2

Božić, M., Đureta, F., Goršić, E., Vedriš, M., 2020: Influence of a measurer and measurement errors on measurement of a tree diameter. Šumarski list 144(5-6): 233-245. http://doi. org/10.31298/s1.144.5-6.1

Bradshaw, F.J., 1972: Upper stem diameter measurements with the aid of 35 millimeter photographs. Australian Forest Research 6: 17-20.

Brickell, J.E., 1976: Bias and precision of the Barr and Stroud dendrometer under field conditions. U.S. Department of 
Agriculture, Forest Service, Intermountain Forest and Range Experiment Station, Ogden, UT. Research Paper INT-186.

Celes, C.H.S., Araujo, R.F.D., Emmert, F., Lima, A.J.N., Campos, M.A.A., 2019: Digital approach for measuring tree diameters in the Amazon forest. Floresta e Ambiente 26(1): e20160384. http://doi.org/10.1590/2179-8087.038416

Clark, N.A., Wynne, R.H., Schmoldt, D.L., 2000a: A review of past research on dendrometers. Forest Science 46(4): 570576. https://doi.org/10.1093/forestscience/46.4.570

Clark, N.A., Wynne, R.H., Schmoldt, D.L., Winn, M., 2000b: An assessment of the utility of a non-metric digital camera for measuring standing trees. Computers and Electronics in Agriculture 28(2): 151-169. https://doi.org/10.1016/S01681699(00)00125-3

Clarke, T.A., 1995: An analysis of the prospects for digital close-range photogrammetry. ISPRS Journal of Photogrammetry and Remote Sensing 50(3): 4-7. https://doi. org/10.1016/0924-2716(95)91285-R

Day, R.W., Quinn, G.P., 1989: Comparisons of treatments after an analysis of variance in ecology. Ecological Monographs 59(4): 433-463. https://doi.org/10.2307/1943075

Dick, A.R., Kershaw Jr, J.A., MacLean, D.A., 2010: Spatial tree mapping using photography. Northern Journal of Applied Forestry 27(2): 68-74. https://doi.org/10.1093/njaf/27.2.68

Dixon, R.G., 1973: The Samoan diameter stick. The Commonwealth Forestry Review 52(3): 266-269.

Dunnett, C.W., 1980: Pair wise multiple comparisons in the unequal variance case. Journal of the American Statistical Association 75(372): 796-800.

Grosenbaugh, L.R., 1963: Optical dendrometers for out-ofreach diameters: A conspectus and some new theory. Forest Science 9(Supplement - 1): 1-47. https://doi.org/10.1093/forestscience/9.s1.a0001

IBM Corp., 2013: IBM SPSS Statistics for Windows, Version 22.0. IBM Corp., Armonk, NY.

Jackson, A.G., 1911: The Biltmore stick and its use on national forests. Journal of Forestry 9(3): 406-411. https://doi. org/10.1093/jof/9.3.406

Juujarvi, J., Heikkonen, J., Brandt, S.S., Lampinen, J., 1998: Digital-image-based tree measurement for forest inventory. In Intelligent Robots and Computer Vision XVII: Algorithms, Techniques, and Active Vision 3522: 114-123. International Society for Optics and Photonics.

Kalliovirta, J., Laasasenaho, J., Kangas, A., 2005: Evaluation of the laser-relascope. Forest Ecology and Management 204(2-3): 181-194. https://doi.org/10.1016/j.foreco.2004.09.020

Kershaw, J.A.Jr., Ducey, M.J., Beers, T.W., Husch, B., 2017: Forest mensuration. John Wiley \& Sons, Inc., Hoboken, NJ.

Levene, H., 1960: Robust tests for the equality of variance. Contributions to Probability and Statistics, Olkin, I. (ed.). Stanford University Press, Palo Alto, CA., 278-292 p.

Liu, S., Bitterlich, W., Cieszewski, C.J., Zasada, M.J., 2011: Comparing the use of three dendrometers for measuring di- ameters at breast height. Southern Journal of Applied Forestry 35(3): 136-141. https://doi.org/10.1093/sjaf/35.3.136

Luoma, V., Saarinen, N., Wulder, M.A., White, J.C., Vastaranta, M., Holopainen, M., Hyyppä, J., 2017: Assessing precision in conventional field measurements of individual tree attributes. Forests 8(2): 38. https://doi.org/10.3390/f8020038

Marsh, E.K., 1952: Measurement of standing sample trees. In British Commonwealth Forestry Conference 1952: Ottawa.

Melkas, T., Vastaranta, M., Holopainen, M., 2008: Accuracy and efficiency of the laser-camera. In Proceedings of SilviLaser 2008: $8^{\text {th }}$ International Conference on LiDAR Applications in Forest Management and Inventory, Hill, R.A., Rosette, J., and Suárez, J. (eds.). Heriot-Watt University, Edinburgh, UK., 315-324 p.

Moder, K., 2010: Alternatives to F-test in one way ANOVA in case of heterogeneity of variances (a simulation study). Psychological Test and Assessment Modeling 52(4): 343-353.

Molinier, M., López-Sánchez, C.A., Toivanen, T., Korpela, I., Corral-Rivas, J.J., Tergujeff, R., Häme, T., 2016: RelasphoneMobile and participative in situ forest biomass measurements supporting satellite image mapping. Remote Sensing 8(10): 869. https://doi.org/10.3390/rs8100869

Moran, L.A., Williams, R.A., 2002: Field note-Comparison of three dendrometers in measuring diameter at breast height. Northern Journal of Applied Forestry 19(1): 28-33. https:// doi.org/10.1093/njaf/19.1.28

Shingala, M.C., Rajyaguru, A., 2015: Comparison of post hoc tests for unequal variance. International Journal of New Technologies in Science and Engineering 2(5): 22-33.

Siipilehto, J., Lindeman, H., Vastaranta, M., Yu, X., Uusitalo, J., 2016: Reliability of the predicted stand structure for clearcut stands using optional methods: airborne laser scanningbased methods, smartphone-based forest inventory application Trestima and pre-harvest measurement tool EMO. Silva Fennica 50(3): article id 1568. https://doi.org/10.14214/sf.1568

Silva, B.H.L., 2018: Comparação entre estimativas de altura de eucalipto realizadas pelo MOTI e pelo clinômetro HAGLOF. Technical Report. Department of Forest Engineering, University of Federal dos Vales do Jequitinhonha e Mucuri, Diamantina, Minas Gerais, Brazil. https://doi.org/10.3390/ rs8100869

Skovsgaard, J.P., Johannsen, V.K., Vanclay, J.K., 1998: Accuracy and precision of two laser dendrometers. Forestry 71(2): 131-139. https://doi.org/10.1093/forestry/71.2.131

Takahashi, M., Saito, K., Shiraishi, N., Iehara, T., Takahashi, F., 1997: A photo based measurement system using a measuring camera. Journal of Forest Planning 3(1): 1-9. https://doi. org/10.20659/jfp.3.1_1

van Laar V.A., Akça, A., 2007: Forest mensuration (Vol. 13). Springer Science \& Business Media, Dordrecht, The Netherlands.

Vastaranta, M., Latorre, E.G., Luoma, V., Saarinen, N., Holopainen, M., Hyyppä, J., 2015: Evaluation of a smartphone app for forest sample plot measurements. Forests 6(4): 1179-1194. https://doi.org/10.3390/f6041179 
Vastaranta, M., Melkas, T., Holopainen, M., Kaartinen, H., Hyyppä, J., Hyyppä, H., 2009: Laser-based field measurements in tree-level forest data acquisition. Photogrammetric Journal of Finland 21(2): 51-61.

Vatandaşlar, C., Zeybek, M., 2020: Application of handheld laser scanning technology for forest inventory purposes in the NE Turkey. Turkish Journal of Agriculture and Forestry 44(3): 229-242. https://doi.org/10.3906/tar-1903-40

Weaver, S.A., Ucar, Z., Bettinger, P., Merry, K., Faw, K., Cieszewski, C.J., 2015: Assessing the accuracy of tree diameter measurements collected at a distance. Croatian Journal of Forest Engineering 36(1): 73-83.

Weinberg, S.L., Abramowitz, S.K., 2016: Statistics using IBM SPSS: An integrative approach. Cambridge University Press, New York.
Williams, M.S., Cormier, K.L., Briggs, R.G., Martinez, D.L., 1999: Evaluation of the Barr \& Stroud FP15 and Criterion 400 laser dendrometers for measuring upper stem diameters and heights. Forest Science 45(1): 53 -61. https://doi.org/10.1093/ forestscience $/ 45.1 .53$

Xie, Y., Zhang, J., Chen, X., Pang, S., Zeng, H., Shen, Z., 2020: Accuracy assessment and error analysis for diameter at breast height measurement of trees obtained using a novel backpack LiDAR system. Forest Ecosystems 7: 1-11. https:// doi.org/10.1186/s40663-020-00237-0

Yan, J., He, G., Basiri, A., Hancock, C., 2020: 3-D passive-vision-aided pedestrian dead reckoning for indoor positioning. IEEE Transactions on Instrumentation and Measurement 69(4): 1370-1386. https://doi.org/10.1109/TIM.2019. 2910923

(C) 2022 by the authors. Submitted for possible open access publication under the terms and conditions of the Creative Commons Attribution (CC BY) license (http://creativecommons.org/licenses/by/4.0/).

Received: May 25, 2020

Accepted: March 02, 2021
Authors' addresses:

Asst. prof. Zennure Ucar, $\mathrm{PhD}$ * e-mail: zennure.ucar@ikc.edu.tr İzmir Katip Çelebi University

Faculty of Forestry

Department of Forest Engineering

Çiğli, İzmir, 35620

TURKEY

Ahmet Salih Değermenci, PhD

e-mail: ahmetdegermenci@duzce.edu.tr

Assoc. prof. Hayati Zengin, PhD

e-mail: hayatizengin@duzce.edu.tr

Duzce University

Faculty of Forestry

Department of Forest Engineering

Duzce 81620

TURKEY

Prof. Pete Bettinger, PhD

e-mail: pbettinger@warnell.uga.edu

University of Georgia

Warnell School of Forestry and Natural Resources

Athens, GA 30602

USA

* Corresponding author 